\title{
Investigating Tetrel based Neutral Frustrated Lewis Pairs for Hydrogen Activation
}

\author{
Pallavi Sarkar, ${ }^{[\mathrm{a}]}$ Shubhajit Das, ${ }^{[\mathrm{a}][\mathrm{b}]}$ and Swapan K. Pati $*[\mathrm{a}]$

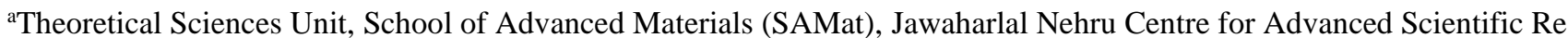 \\ search, Bangalore-560064, India \\ ${ }^{b}$ Present Address: Laboratory for Computational Molecular Design, Institute of Chemical Sciences and Engineering, Ecole Polytechnique \\ Fed'eral’e de Lausanne (EPFL), 1015 Lausanne, Switzerland
}

\begin{abstract}
Tetrel Lewis acids are a prospective alternative to commonly employed neutral boranes in frustrated Lewis pair (FLP) chemistry. While cationic tetrylium Lewis acids, being isolobal and iso(valence)electronic, are a natural replacement to boranes, neutral tetrel Lewis acids allude as less trivial options due to the absence of a formally empty p orbital on the acceptor centre. Recently a series of intramolecular geminal FLPs $\left(\mathbf{C}_{2} \mathbf{F}_{5}\right)_{3} \mathbf{E}-\mathbf{C H}_{2}-\mathbf{P}(\mathbf{t B u})_{2}(\mathrm{E}=\mathrm{Si}, \mathrm{Ge}, \mathrm{Sn})$ featuring neutral tetrel atoms as acceptor site, were reported for activation of small molecules including $\mathrm{H}_{2}$. In this work, through density functional theory computations, we elucidate the general mechanistic picture of $\mathrm{H}_{2}$ activation by this family of FLPs. Our findings reveal that the acceptor atom derives the required Lewis acidity utilizing the antibonding orbitals of its adjacent bonds with the individual contributions depending on the identity of the acceptor and the donor atoms. By varying the identity of the Lewis acid and Lewis base atoms and attached substituents, we unravel their interplay on the energetics of the $\mathrm{H}_{2}$ activation. We find that switching the donor site from $\mathrm{P}$ to $\mathrm{N}$ significantly affects the synchronous nature of the bond breaking/formations along the reaction pathway and as a result, N-bearing FLPs have a more favourable $\mathrm{H}_{2}$ activation profile than those with $\mathrm{P}$. Our results are quantitatively discussed in detail within the framework of Activation Strain Model of reactivity along with the Energy Decomposition Analysis method. Finally, the reductive elimination decomposition route pertinent to the plausible extension of the $\mathrm{H}_{2}$ activation to catalytic hydrogenation by these FLPs is also examined.
\end{abstract}

\section{INTRODUCTION}

The activation of the apolar $\mathrm{H}-\mathrm{H}$ bond of hydrogen molecule $\left(\mathrm{H}_{2}\right)$ is challenging as well as the key step in any direct catalytic hydrogenation. ${ }^{1-5}$ Thus, systems capable of activating $\mathrm{H}_{2}$ can potentially act as hydrogenation catalysts. Transition metal (TM) complexes are well-known for their ability to activate $\mathrm{H}_{2}$ by virtue of their partially filled d-manifold providing both donor and acceptor orbitals for synergistic $\mathrm{H}_{2}$ activation. In the past two decades, research on the main group mediated $\mathrm{H}_{2}$ activation has received immense attention with the ultimate goal of replacing TMs in hydrogenation catalysis. One prominent strategy along this route involves the utilization of Frustrated Lewis Pairs (FLPs), which deploy sterically crowded, unquenched combinations of Lewis acids (LAs) and Lewis bases (LBs) for heterolytic cleavage of $\mathrm{H}_{2}$ in the manner of TMs. ${ }^{6-14}$ This remarkable chemistry has played a pivotal role in the development of TM-free routes to catalytic hydrogenations. ${ }^{15-20}$

A wide range of LA/LB combinations has been developed and utilized for $\mathrm{H}_{2}$ activation in FLP literature. Compared to the diverse spectrum of the employed LB components, the range of LA has been quite confined. In fact, during the early stages of FLP chemistry perfluorinated boranes were used heavily despite their drawbacks such as moisture sensitivity and low functional group tolerance. ${ }^{21-24}$ Nevertheless, these limitations of boranes drove a substantial amount of research towards exploring new options. ${ }^{25,26}$ Recently, group 14 and group 15

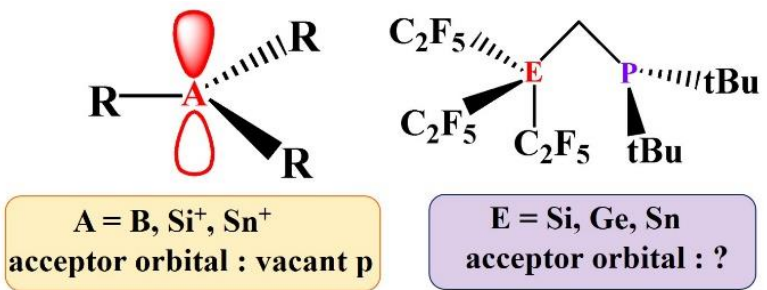

Figure 1. Group 13 and Group 14 LAs with $\mathrm{sp}^{2}$ acceptor centre used in FLP chemistry (Left) Intramolecular FLP featuring neutral tetrel acceptor centre (Right).

LAs were introduced in FLP chemistry including tetrylium ${ }^{27-33}$ and phosphonium LAs. ${ }^{34-44}$ Cationic tetrylium LAs were used with amines to effect $\mathrm{H}_{2}$ activation. Especially Stannyliums were demonstrated as promising FLP LAs due to their excellent moisture tolerance leading to efficient catalytic hydrogenation protocols with a wide range of substrate scope. ${ }^{45,46}$ The reactivity of a vast majority of these LA/LB combinations utilized for $\mathrm{H}_{2}$ activation can be explained from a largely accepted mechanistic model $^{47}$ that involves two cooperative electron transfer (ET) process, namely LB $\rightarrow \sigma^{*}\left(\mathrm{H}_{2}\right)$ and $\sigma\left(\mathrm{H}_{2}\right) \rightarrow$ LA 
electron donations, leading to the progressive weakening of the $\mathrm{H}-\mathrm{H}$ bond with concomitant LA-H and LB-H bond formation. ${ }^{48-}$

${ }^{53}$ The model was initially proposed from pioneering works by Papai on B/P or B/N FLP combinations. ${ }^{48-53}$ It was shown that, typically, the empty $\mathrm{p}_{\mathrm{z}}$ orbital on the boron atom $\left(\mathrm{sp}^{2}\right.$ hybridized) plays the role of the acceptor orbitals to receive electrons from $\sigma\left(\mathrm{H}_{2}\right)$ orbital. A similar mechanism also prevails for the FLPs with tetrylium LAs which are isolobal and iso(valence)electronic with boranes. ${ }^{54-57}$

Very recently, neutral tetrel LAs were introduced in FLP chemistry. Mitzel et al. reported a series of intramolecular geminal FLPs featuring neutral tetrel $(\mathrm{E})$ atoms in combination with $\mathrm{P}$ donors $\left(\mathrm{C}_{2} \mathrm{~F}_{5}\right)_{3} \mathrm{E}-\mathrm{CH}_{2}-\mathrm{P}(\mathrm{tBu})_{2}\left(\mathrm{E}=\mathrm{Si},{ }^{58} \mathrm{Ge},{ }^{59} \mathrm{Sn}^{60}\right)$. They were utilized for activation of a variety of small molecules (such as $\mathrm{CO}_{2}, \mathrm{SO}_{2}$ etc.) including $\mathrm{H}_{2}$. For example, the $\mathrm{Si} / \mathrm{P}$ and the $\mathrm{Sn} / \mathrm{P}$ combinations were shown to cleave $\mathrm{H}_{2}$ under ambient conditions and as such these FLPs hold great potential for being prospective hydrogenation catalysts. ${ }^{61}$ Nevertheless, despite considerable experimental works, one point that remains to be fully understood is how these neutral E LA sites participate in cooperative $\mathrm{H}_{2}$ activation. The ambiguity in the mechanistic picture arises from the fact that the $\mathrm{E}$ atoms have no formally empty $\mathrm{p}$ orbital to engage into electron transfer with the $\mathrm{H}_{2}$ molecule. In this article, we attempt to answer this question through a detailed computational mechanistic investigation of the $\mathrm{H}_{2}$ activation by a series of intramolecular FLPs bearing neutral $\mathrm{E}$ atoms. Our findings reveal how various combinations of $\mathrm{E}$ and donor sites (D) influence the energetics of the $\mathrm{H}_{2}$ activation. We expect that the results obtained in this study would pave the development of new catalytic protocols using these new E-based FLPs.

\section{RESULTS AND DISCUSSION}

To understand the mechanism and various factors influencing the $\mathrm{H}_{2}$ activation process, we examined a series of 18 intramolecular FLPs comprised of Si, Ge, Sn LAs along with N and $\mathrm{P}$ donor centres. In general, these FLPs are denoted as $\mathbf{1}$ (see Scheme 1) while discussing specific systems we have used the notation Y-E-D (Y=intermediate or transition state).

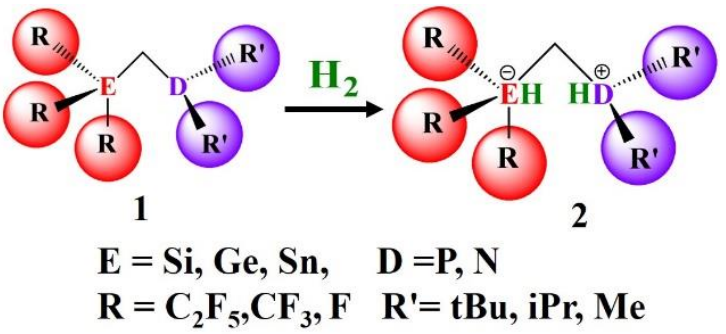

Scheme 1. General structural framework and the series of the geminal FLP systems considered in this study for $\mathrm{H}_{2}$ activation reaction. Here $\mathrm{E}=$ Tetrel centre and $\mathrm{D}=$ Donor centre.

Furthermore different substituents $\left(\mathrm{R}=\mathrm{C}_{2} \mathrm{~F}_{5}, \mathrm{CF}_{3}, \mathrm{~F} ; \mathrm{R}\right.$ '=tBu,iPr, $\mathrm{Me}$ ) on the LA and LB centres are used to vary the steric as well as the electronic environment around the active sites. Note that, majority of the investigated FLPs are already synthesized by the group of Mitzel. ${ }^{62-64} \mathrm{~A}$ few additional combinations were used to complement the pool for a comprehensive understanding of the $\mathrm{H}_{2}$ activation step.

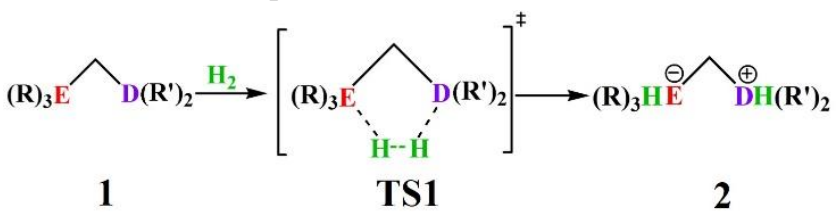

Scheme 2. Schematic representation of $\mathrm{H}_{2}$ activation reaction by 1 .

We begin by analyzing the optimized geometries of three representatives FLPs, $\left(\mathrm{C}_{2} \mathrm{~F}_{5}\right)_{3} \mathrm{Si}-\mathrm{CH}_{2}-\mathrm{P}(\mathrm{tBu})_{2}$ (hereafter denoted as 1-Si-P), $\left(\mathrm{C}_{2} \mathrm{~F}_{5}\right)_{3} \mathrm{Ge}-\mathrm{CH}_{2}-\mathrm{P}(\mathrm{tBu})_{2}(\mathbf{1 - G e}-\mathrm{P})$ and $\left(\mathrm{C}_{2} \mathrm{~F}_{5}\right)_{3} \mathrm{Sn}-\mathrm{CH}_{2}-$ $\mathrm{P}(\mathrm{tBu})_{2}$ (1-Sn-P) (see Figure-S1 and Table S1). We find that these geminal systems feature a wide $\angle \mathrm{E}-\mathrm{CH}_{2}-\mathrm{P}$ angle. For example, 1-Si-P and 1-Ge-P have the $\angle \mathrm{E}-\mathrm{CH}_{2}-\mathrm{P}$ of value of $119.1^{\circ}$ and $117.5^{\circ}$ respectively, which are in good agreement with the experimentally obtained value of $120.4^{\circ}$ and $117.8^{\circ}$ whereas for 1-Sn-P, the $\angle \mathrm{Sn}-\mathrm{CH} 2-\mathrm{P}$ angle is of $114.8^{\circ}$ which is close to value of $113.9^{\circ}$ obtained from solid-state structure. The wide-angle prevents any direct interaction between the $\mathrm{E}$ and the $\mathrm{P}$ sites which is reflected by a large separation of around $3.0 \AA$ between the acidic and basic sites in these molecules. In contrast, the corresponding boron analogue $\left(\mathrm{C}_{2} \mathrm{~F}_{5}\right)_{2} \mathrm{~B}-\mathrm{CH}_{2}-$ $\mathrm{P}(\mathrm{tBu})_{2}$, is known to exist in the "quenched ring-closed form" compared to the ring-opened isomer. ${ }^{65}$ These observations suggested that these geminal systems possess a significant FLPtype behaviour and therefore the unquenched reactivity at the acidic and basic sites of these systems can be utilized for the heterolytic splitting of the hydrogen molecule.

Scheme 2 depicts the mechanism of $\mathrm{H}_{2}$ activation by 1 . Initially, $\mathbf{1}$ forms a reactant complex (1-RC, see Figure S3 for geometry optimized structures of the relevant stationary points on the potential energy surface.) which results from a side-on interaction between $\mathrm{H}_{2}$ and the $\mathrm{E}$ atom. 1-RC passes through a single concerted five-membered transition state, TS1. At TS1, the $\mathrm{H}-\mathrm{H}$ bond elongates from its equilibrium value $(0.74 \AA)$ which indicates the weakening of the $\mathrm{H}-\mathrm{H}$ bond and eventually it leads to a heterolytic cleavage of the $\mathrm{H}_{2}$ molecule. As a result, the hydride shifts to the Tr site while the proton attaches to the $\mathrm{D}$ atom, leading to the formation of the zwitterionic product 2.

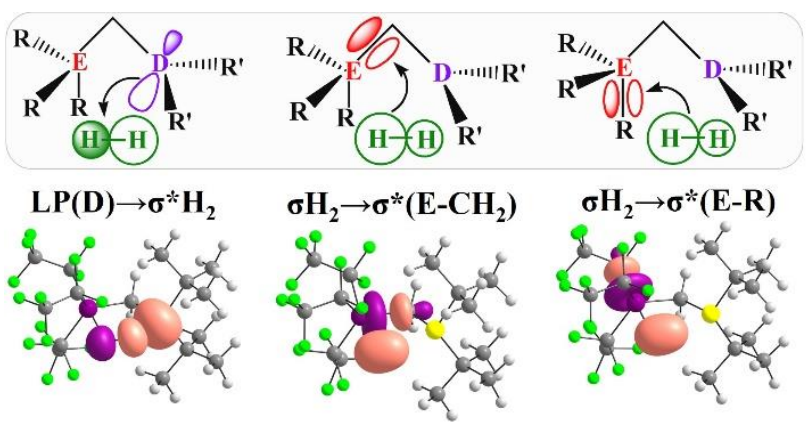

Figure 2. Schematic representation of the mechanism of $\mathrm{H}_{2}$ activation by 1 (top). Major orbital interactions involved in the $\mathrm{H}_{2}$ splitting by $\mathbf{1 - S i - P}$ (bottom). 


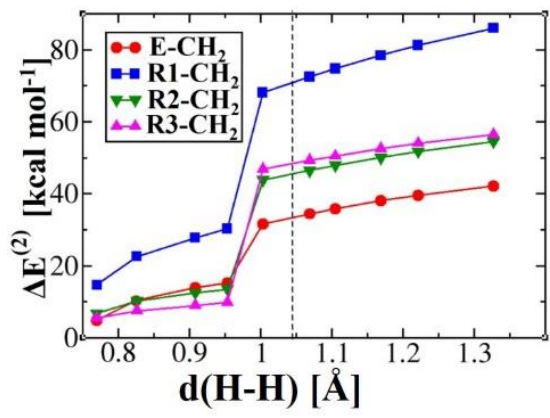

(a)

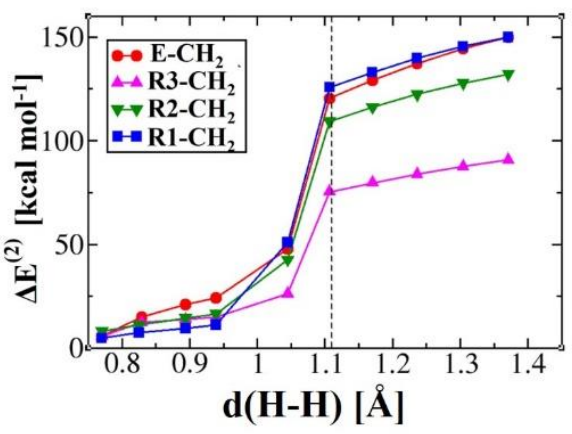

(b)

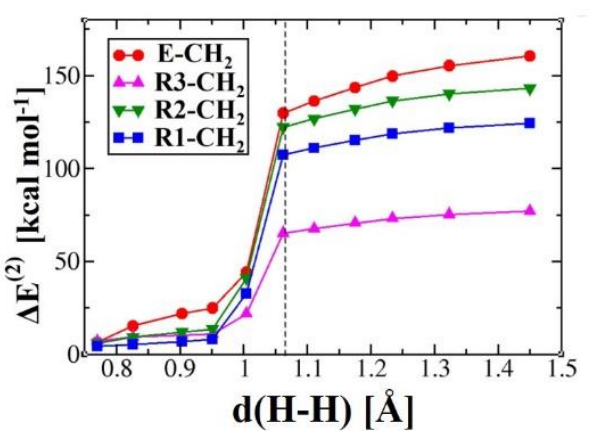

(c)

Figure 3. Donor-acceptor interaction energies estimated at the second-order perturbation theory level $\Delta \mathrm{E}^{(2)}$ associated with interaction $\sigma \mathrm{H}_{2} \rightarrow \sigma^{*}\left(\mathrm{E}-\mathrm{CH}_{2}\right) / \sigma^{*}(\mathrm{R}-\mathrm{E})$ along the minimum energy path for (a) 1-Si-P (b) 1-Ge-P and (c) 1-Sn-P. The dotted lines denote the respective TSs.

Given the apparent resemblance of the optimized geometries of the stationary points, we expect no major deviation in the mechanistic pathway of $\mathrm{H}_{2}$ activation for the considered FLPs. Next, we turned our attention to establish a clear mechanistic picture of the $\mathrm{H}_{2}$ activation pathway by $\mathbf{1}$. We already mentioned that the two major ET events leading to the heterolytic cleavage of the H-H bond by a typical FLP involve (1) ET from the $\sigma$ bonding orbital of the $\mathrm{H}_{2}$ to the empty orbital (typically LUMO) of the acceptor atom, and (2) simultaneous electron transfer from a filled donor orbital to the $\sigma^{*}$ antibonding orbital of the $\mathrm{H}-\mathrm{H}$ bond. While we envisage that on the donor site this picture remains the same for $\mathbf{1}$, on the acid site there ought to be a different mechanistic rationale since there exist no formally empty orbitals. To find potential acceptor orbital(s), we first examined the FMOs of $\mathbf{1}$ (see Figure S4). While the HOMO is located over the donor atom ( $\mathrm{N}$ or $\mathrm{P}$ ), the LUMO is found to be distributed over the $\mathrm{E}$ atom as well as over the $\mathrm{E}-\mathrm{CH}_{2}$ and $\mathrm{E}-\mathrm{R}$ bonds. NBO analysis identifies the nature of these two orbitals as $\sigma^{*}\left(\mathrm{E}-\mathrm{CH}_{2}\right)$ orbital and $\sigma^{*}(\mathrm{E}-\mathrm{R})$ orbital. The major difference upon varying the $\mathrm{E}$ atom is the composition of the LUMO, which changes from mainly $\sigma^{*}(\mathrm{E}-\mathrm{R})$ orbital for $\mathrm{Si}$ to more or less an equal distribution of both the orbitals for Sn. NBO analysis of TS1 clearly demonstrates the involvement of these two orbitals in the $\mathrm{H}_{2}$ cleavage step. For example, We find substantial interaction between $\sigma(\mathrm{H}-\mathrm{H})$ orbital and $\sigma^{*}(\mathrm{R}-\mathrm{Si})$ and $\sigma^{*}(\mathrm{Si}-$ $\mathrm{CH}_{2}$ ) orbitals (estimated $2^{\text {nd }}$ order PT level $\Delta \mathrm{E}^{(2)}=26.9$ and 19.8 $\mathrm{kcal} / \mathrm{mol}$ respectively) in the structure of TS1-Si-N. For TS1Si-P, these interactions are already at a very advanced stage and we find that $\sigma$ orbital of the newly formed $\mathrm{Si}-\mathrm{H}$ bond is engaged in interaction with $\sigma^{*}(\mathrm{R}-\mathrm{Si})$ and $\sigma^{*}\left(\mathrm{Si}-\mathrm{CH}_{2}\right)$ orbitals. This is presumably due to the different positions of those two TS structures on the PES as evident from their $\mathrm{H}-\mathrm{H}$ distances $(0.922 \AA$ vs $1.046 \AA$ for $\mathbf{1 - S i - N}$ and 1-Si-P, respectively). Thus, to have a fair comparison, we performed NBO analysis throughout the entire reaction pathway. Our results reveal that due to the preorganized nature of the intramolecular FLP 1, from an early stage of the reaction the lone pair (LP) of D begins electron donation to $\sigma^{*}(\mathrm{H}-\mathrm{H})$ along with concomitant $\mathrm{ET}$ to $\sigma^{*}\left(\mathrm{E}-\mathrm{CH}_{2}\right)$ and $\sigma^{*}(\mathrm{E}-\mathrm{R})$ orbitals from $\sigma \mathrm{H}_{2}$ orbital (see Figure 2 and Figure-S5). These two synergistic interactions develop further with the advancement of the reaction resulting in the progressive weakening of the $\mathrm{H}-\mathrm{H}$ bond which ultimately leads to the formation of the product 2 . Note that, Fernandez et al. reported similar electron donation from the isocyanate moiety to the $\sigma^{*}(\mathrm{E}-\mathrm{R})$ orbital during their computational investigation of the reaction between PhCNO and these intramolecular FLP systems. $^{66}$

To investigate the role of the four $\sigma^{*}$ orbitals as the acceptor orbital further, the estimated D-A interaction energy $\left(\Delta \mathrm{E}^{(2)}\right.$ value ) is plotted as a function of $\mathrm{H}-\mathrm{H}$ stretch (see Figure 3 ). While for 1-Si-P, one of the $\sigma^{*}(\mathrm{R}-\mathrm{E})$ orbital acts as the predominant acceptor orbital (blue line), contributions from $\sigma^{*}($ E- $\mathrm{CH}_{2}$ ) orbital (red line) becomes more and more significant upon changing the identity of the $\mathrm{E}$ by moving down the group. In fact, $\sigma^{*}\left(\mathrm{E}-\mathrm{CH}_{2}\right)$ orbital is the predominant acceptor orbital in the case of 1-Sn-P. The increasing influence of $\sigma^{*}\left(\mathrm{E}-\mathrm{CH}_{2}\right)$ orbital can be correlated with the increasing Lewis acidity of $\mathrm{E}$ atoms in $\mathbf{1}$ along with the group.

Swapping the $\mathrm{D}$ site from $\mathrm{P}$ to $\mathrm{N}$ has a similar effect as illustrated in Figure S6. Due to the higher electronegativity of nitrogen, the bridgehead carbon acquires a more positive charge which instigates the $\sigma^{*}\left(\mathrm{E}-\mathrm{CH}_{2}\right)$ orbital a better acceptor orbital compared to when the donor atom is $\mathrm{P}$. Overall, our findings reveal that the $\sigma^{*}\left(\mathrm{E}-\mathrm{CH}_{2}\right)$ and $\sigma^{*}(\mathrm{R}-\mathrm{E})$ orbitals play a very crucial role in $\mathrm{H}_{2}$ activation by accepting the electron density from the $\sigma \mathrm{H}_{2}$ orbital, particularly at the early stage of the reaction which eventually helps to weaken the $\mathrm{H}-\mathrm{H}$ bond. Thus, the neutral $\mathrm{E}$ atoms despite having no formally vacant $\mathrm{p}$ orbitals derive a considerable Lewis acidity from not only the $\sigma^{*}$ orbitals of highly electron-withdrawing $\mathrm{R}$ groups attached to it but also from the $\sigma^{*}\left(\mathrm{E}-\mathrm{CH}_{2}\right)$ orbital.

Having settled the mechanism of $\mathrm{H}_{2}$ activation we now compare the reactivity of the FLPs. Figure 4 shows the computed activation barriers along with the corresponding reaction free energies for all the FLPs in scheme1. We find that for all the systems the $\mathrm{H}_{2}$ splitting reaction is endergonic in nature. Moreover, the activation barriers differ widely among the candidates spanning a range of $12-35 \mathrm{kcal} / \mathrm{mol}$. It is also observed with a particular structural framework with different $\operatorname{Tr}$ centres, the $\mathrm{H}_{2}$ activation barrier follows the order $\mathrm{Ge}>\mathrm{Si}>\mathrm{Sn}$. This computed trend is consistent with experimental observations that 1-Si-P 


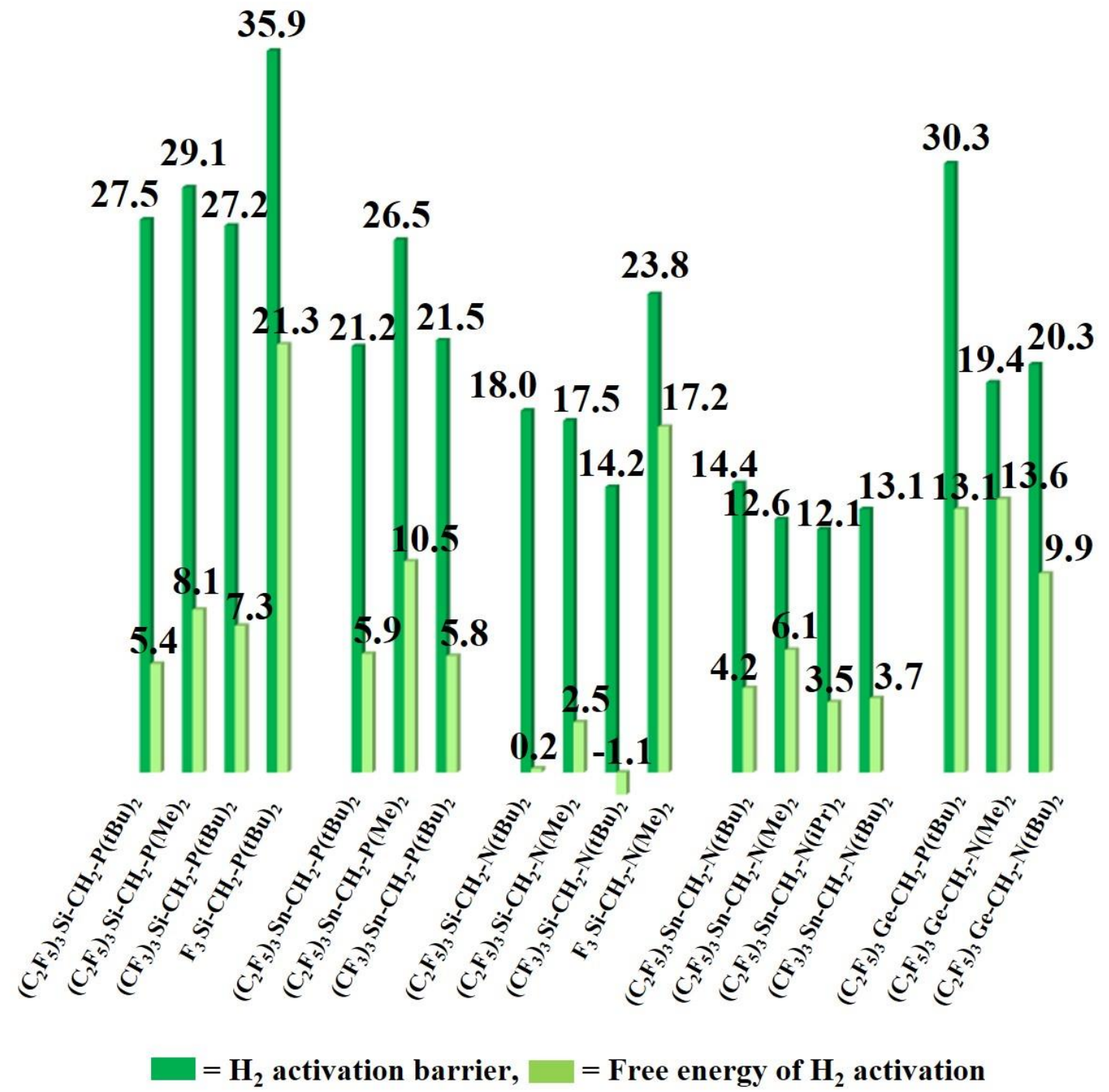

Figure 4. The computed values of $\mathrm{H}_{2}$ activation barrier and Gibbs Free energy of $\mathrm{H}_{2}$ activation for all FLPs. All energies are given in $\mathrm{kcal} / \mathrm{mol}$.

and 1-Sn-P activate hydrogen whereas 1-Ge-P turned out to be inactive in this respect. Figure 4 also reveals that the different steric profile of $\mathrm{R}$ and $\mathrm{R}$ ' groups attached to the acidic and basic sites can also influence the energetics of the $\mathrm{H}_{2}$ activation process. For example, the replacement of the bulky $-\mathrm{C}_{2} \mathrm{~F}_{5}$ group by the $-\mathrm{CF}_{3}$ group in the FLPs with $\mathrm{N}$ atom reduces the activation barrier as well as the reaction free energy. Nonetheless, this effect is less significant for the corresponding P containing FLP. Regardless of the donor site, replacing the R group from $-\mathrm{C}_{2} \mathrm{~F}_{5}$ to sterically less demanding -F group has a significant impact on the energetics of $\mathrm{H}_{2}$ activation with extremely endergonic reactions and high activation barriers. This result is in accordance with the experimental observation that $\mathbf{F}_{3} \mathbf{S i}-\mathbf{C H}_{2}-\mathbf{P}(\mathbf{t B u})_{2}$ fails to activate the dihydrogen. ${ }^{64} \mathrm{~A}$ careful inspection of the relevant structures reveal that in $\mathbf{F}_{3} \mathbf{S i}-\mathbf{C H}_{2}-\mathbf{P}(\mathbf{t B u})_{2}$, the coordination geometry at $\mathrm{Si}$ is an almost undistorted tetrahedral (three F-Si-C angles: $113.6^{0}, 113.2^{0}$ and $\left.110.4^{0}\right)$ whereas in $\left(\mathbf{C}_{2} \mathbf{F}_{5}\right)_{3} \mathbf{S i}$ $\mathbf{C H}_{2}-\mathbf{P}(\mathbf{t B u})_{2}$ the Si centre resides in a more distorted coordination environment (with three C-Si-C1 angles: $109.4^{0}, 103.4^{0}$ and $116.3^{\circ}$ ). However, the TS1 geometries for both FLPs feature a very similar distorted pentacoordinate geometry around the $\mathrm{Si}$ atom (at TS1, three F-Si-C angles: $124.3^{\circ}, 116.1^{\circ}$ and $91.8^{0}$; three C-Si-C1 angles: $120.2^{\circ}, 118.2^{\circ}$ and $90.5^{\circ}$ ) which results in a larger rearrangement and therefore a higher strain for the $F_{3}$ substituted FLP systems. The influence of the R' group attached to the donor site of these intramolecular systems is also explored by varying the bulky -tBu group with the smaller -Me group that increases the endothermicity of the reaction. Interestingly, reducing the steric crowding at the D site slightly lowers the $\mathrm{H}_{2}$ activation barrier for N-bearing FLPs, i.e, the activation barrier for $\left(\mathbf{C}_{2} \mathbf{F}_{5}\right)_{3} \mathbf{S n}-\mathbf{C H}_{2}-\mathbf{N}(\mathbf{M e})_{2}$ is reduced to 12.6 $\mathrm{kcal} / \mathrm{mol}$ compared to $\left(\mathbf{C}_{2} \mathbf{F}_{5}\right)_{3} \mathbf{S n}-\mathbf{C H}_{2}-\mathbf{N}(\mathbf{t B u})_{2}$ with a barrier of $14.4 \mathrm{kcal} / \mathrm{mol}$. However, for systems with a $\mathrm{P}$ atom, the opposite trend is observed. These findings indicate that along with the E, the D site also plays an important role in the $\mathrm{H}-\mathrm{H}$ bond cleavage by these geminal FLP systems. This assumption is further supported with another significant observation that in general, FLPs with nitrogen donor have lower activation barriers compared to analogous systems with phosphorous (see Figure 4). Not only the $\mathrm{H}_{2}$ activation barrier, the FLP systems with $\mathrm{N}$ 
as donor make the $\mathrm{H}_{2}$ activation process much less endergonic. Thus, in general, N-containing FLPs exhibit a favourable $\mathrm{H}_{2}$ activation profile compared to those with $\mathrm{P}$.
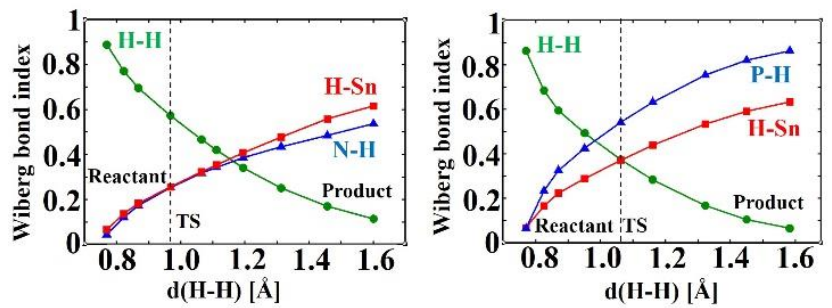

Figure 5. Evolution of the Wiberg bond index values for the $\mathrm{H}$ H, E-H and D-H bonds for (a) 1-Sn-N and (b) 1-Sn-P along the pseudo-IRC path, depicted as a function of the $\mathrm{H}-\mathrm{H}$ bond length. The dotted lines indicate the respective TSs.

To explain such a marked difference in reactivity between 1Sn-P and 1-Sn-N we analyzed their $\mathrm{H}_{2}$ activation profiles in more detail. Figure 5 illustrates the evolution of the E-H, D-H and $\mathrm{H}-\mathrm{H}$ bonds (estimated by Wiberg bond indices plotted along the $\mathrm{Y}$-axis) as a function of the progress of the reaction (estimated by plotting the $\mathrm{H}-\mathrm{H}$ bond length on the $\mathrm{X}$-axis). We find that for 1-Sn-N, from at the very beginning of the reaction, the $\mathrm{N}$ atom engages in a donor-acceptor interaction involving $\sigma^{*}(\mathrm{H}-\mathrm{H})$ orbital. This interaction, together with and $\sigma \mathrm{H}_{2} \rightarrow \sigma^{*}(\mathrm{Sn}-\mathrm{X})$ progressively weaken the $\mathrm{H}-\mathrm{H}$ bond and eventually, the transition state (TS) appears around an $\mathrm{H}-\mathrm{H}$ separation of $0.97 \AA$. At TS1, the $\mathrm{H}-\mathrm{H}$ bond order drops to 0.57 with the concomitant formation of the $\mathrm{Sn}-\mathrm{H}$ and $\mathrm{N}-\mathrm{H}$ bonds (WBI 0.26 and 0.25 for $\mathrm{Sn}-\mathrm{H}$ and $\mathrm{N}-\mathrm{H}$ bond respectively), which appears to be nearly synchronous. On the contrary, for 1Sn-P, these two bond formations appear to be rather asynchronous with the $\mathrm{P}-\mathrm{H}$ bond formation preceding over the formation of the $\mathrm{Sn}-\mathrm{H}$ bond. At the transition state, which appears relatively late at a $\mathrm{H}-\mathrm{H}$ distance of $1.06 \AA$ compared to 1-Sn-N, the computed WBIs are $0.37,0.37$ and 0.54 for $\mathrm{H}-\mathrm{H}$, $\mathrm{Sn}-\mathrm{H}$ and $\mathrm{P}-\mathrm{H}$ bond respectively. The earliness of $\mathrm{P}-\mathrm{H}$ bond formation can be rationalized from the much lower electronegativity of $\mathrm{P}$ (compared to $\mathrm{N}$ ) leading to a more facile electron transfer between the LP of the P atom and $\sigma^{*}(\mathrm{H}-\mathrm{H})$ orbital. Overall, the appearance of the TSs at different stages of the reaction profiles qualitatively explains the difference in the barrier between 1-Sn-N and 1-Sn-P (in accordance with Hammonds postulate).

A quantitative insight into the role of the $\mathrm{D}$ site in the $\mathrm{H}_{2}$ activation process can be obtained by performing a detailed activation-strain-analysis along the entire reaction profile. The activation-strain profiles (ASPs) are constructed with data obtained from the IRC calculations connecting the TS with two corresponding minima for two representative systems 1-Sn-P and 1-Sn-N. As illustrated in Figure 6 (Figure S8 in SI), both FLPs exhibit similar ASP features. A close inspection of Figure 6 suggests that both the strain energy $\left(\Delta \mathbf{E}_{\text {strain }}\right)$ and the interaction energy ( $\left.\Delta \mathbf{E}_{\text {int }}\right)$ terms play a decisive role in the different reactivity of 1-Sn-P and 1-Sn-N. For example, at an $\mathrm{H}-\mathrm{H}$ distance of $1.0 \AA$, $\mathbf{1 - S n}-\mathbf{P}$ shows $\Delta \mathbf{E}_{\text {strain }}$ and $\Delta \mathbf{E}_{\text {int }}$ value of $37.0 \mathrm{kcal} / \mathrm{mol}$ and $-18.2 \mathrm{kcal} / \mathrm{mol}$, respectively, while 1-Sn$\mathbf{N}$ features a lower $\Delta \mathbf{E}_{\text {strain }}$ of $29.4 \mathrm{kcal} / \mathrm{mol}$ and a higher $\Delta \mathbf{E}_{\text {int }}$ value of $-21.6 \mathrm{kcal} / \mathrm{mol}$. Thus, the lower activation barrier in 1Sn-N is attributed to the higher $\Delta \mathbf{E}_{\text {int }}$ and $\Delta \mathbf{E}_{\text {strain }}$ along the entire reaction pathway.
Such differences in the strain energy curve upon changing the $\mathrm{D}$ atom can be associated with the different degree of structural alteration of the FLP motif during the progress of the reaction. One structural parameter that captures this structural difference well is the $\angle \mathrm{E}-\mathrm{CH}_{2}-\mathrm{D}$ angle. While at the very beginning stage of the reaction, 1-Sn-P features a higher $\angle \mathrm{E}-\mathrm{CH}_{2}$-D compared to $\mathbf{1 - S n - N}\left(\angle \mathrm{Sn}-\mathrm{C}-\mathrm{P}=114.8^{0}\right.$ and $\left.\angle \mathrm{Sn}-\mathrm{C}-\mathrm{N}=107.5^{\circ}\right)$, at TS1 this angle becomes nearly the same for both $\left(\angle \mathrm{Sn}-\mathrm{C}-\mathrm{P}=109.1^{0}\right.$ and $\angle \mathrm{Sn}-\mathrm{C}-\mathrm{N}=109.3^{\circ}$, see Figure-S9). This implies that to attain the TS1 geometry, 1-Sn-P experiences a large structural modification $\left(\boldsymbol{\Delta} \boldsymbol{\Theta}=\mathbf{5 . 7 ^ { \mathbf { 0 } }}\right)$ compared to $\mathbf{1 - S n - N}\left(\boldsymbol{\Delta} \boldsymbol{\Theta}=\mathbf{- 1 . 8 ^ { 0 }}\right)$, which is reflected in the higher activation barrier found in the former FLP. This conclusion is further confirmed by splitting the total $\Delta \mathbf{E}_{\text {strain }}$ term into separate contributions arising from both reactants 1 and $\mathrm{H}_{2}$ (see Figure-S10) and the plot manifests higher deformation of 1-Sn-P than 1-Sn-N which explains the observed trend in $\Delta \mathbf{E}_{\text {strain. }}$

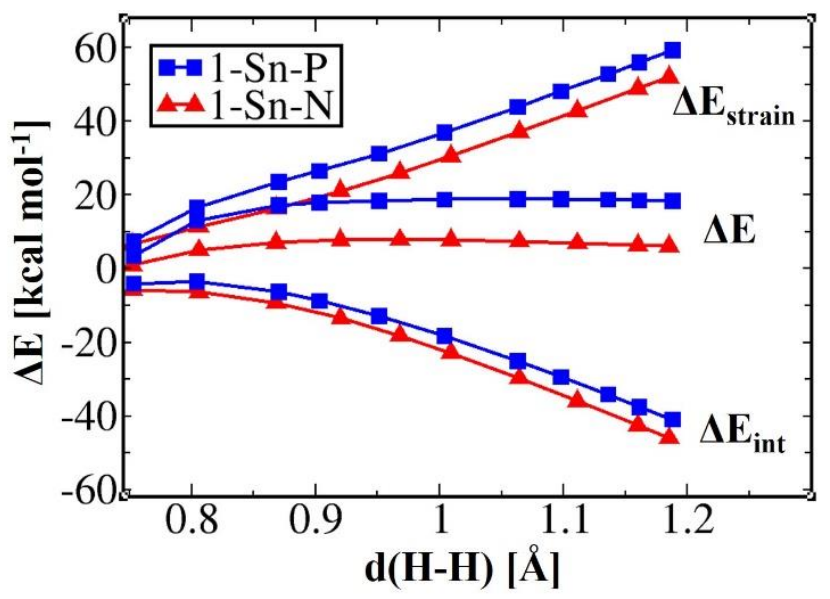

Figure 6. Activation-strain profiles for $\mathrm{H}_{2}$ activation reaction by 1-Sn-P (blue) and 1-Sn-N (red) along the reaction coordinate depicted as a function of the $\mathrm{H}-\mathrm{H}$ distance. The black dots represent the respective TSs.

Next, we analyzed the $\Delta \mathbf{E}_{\text {int }}$ term which also plays a crucial role in determining the activation barrier. To rationalize the difference in the $\mathbf{\Delta} \mathbf{E}_{\mathbf{i n t}}$ curve for the two systems, additional energy decomposition analysis (EDA) is performed which demonstrates (see Figure-7) the different contribution of EDA terms along the reaction coordinate. We find that the contribution of the dispersion forces ( $\left.\Delta \mathbf{E}_{\text {disp }}\right)$ is negligible throughout the entire reaction profile and the repulsive Pauli term $\left(\Delta \mathbf{E}_{\text {pauli }}\right)$ is roughly balanced by stabilizing orbital ( $\left.\Delta \mathbf{E}_{\text {orbital }}\right)$ and electrostatic interactions ( $\left.\Delta \mathbf{V}_{\text {elstat }}\right)$. While $\Delta \mathbf{E}_{\text {orbital }}$ is more or less comparable for Both 1-Sn-P and 1-Sn-N (-102.4 kcal/mol and $-95.4 \mathrm{kcal} / \mathrm{mol}$ at $\mathrm{H}-\mathrm{H}$ distance $1.0 \AA$ for $\mathbf{1 - S n - P}$ and $\mathbf{1 - S n - N}$ respectively) the $\Delta \mathbf{V}_{\text {elstat }}$ which arises due to the zwitterionic nature of the product $\mathbf{2}$, seems to be a crucial determining factor for the different interaction energy curve in 1-Sn-P and 1-Sn-N. For example, at $\mathrm{H}-\mathrm{H}=1.0 \AA, \boldsymbol{\Delta} \mathbf{V}_{\text {elstat }}$ for $\mathbf{1 - S n - P}$ is $-53.3 \mathrm{kcal} / \mathrm{mol}$ but $\mathbf{1 - S n - N}$ has a much larger $\Delta \mathbf{V}_{\text {elstat }}$ value of $-71.9 \mathrm{kcal} / \mathrm{mol}$. Overall, these findings indicate that more stabilizing $\Delta \mathbf{E}_{\text {int }}$ and less destabilizing $\Delta \mathbf{E}_{\text {strain }}$ explain the lower $\mathrm{H}_{2}$ activation barrier in 1-Sn-N compared to $\mathbf{1 - S n - P . ~ T h i s ~ s i m i l a r ~ r a t i o n a l e ~ a p p l i e s ~ t o ~ a l l ~}$ 
systems having $\mathrm{N}$ as $\mathrm{D}$ atom anin general 1-E-N FLPs are predicted to exhibit facile $\mathrm{H}_{2}$ activation reactions.

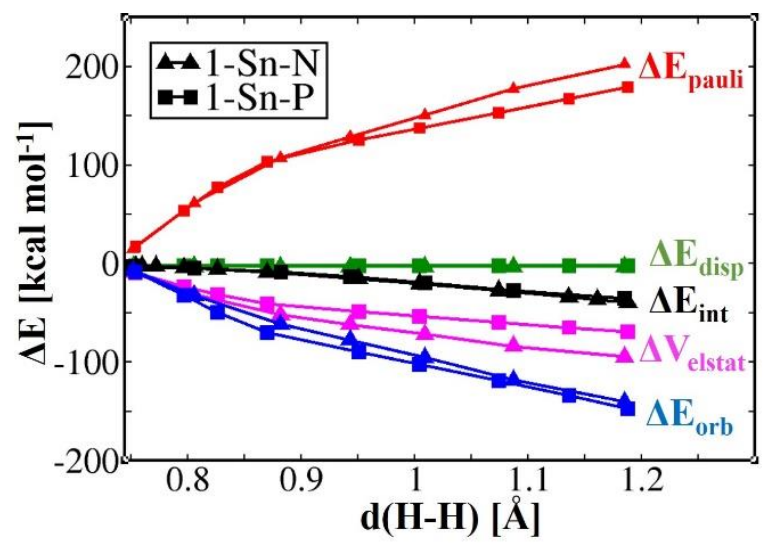

Figure 7. Energy-decomposition analysis for the $\mathrm{H}_{2}$ activation reaction by 1-Sn-P (square) and 1-Sn-N (triangle) along the reaction coordinate depicted as a function of the $\mathrm{H}-\mathrm{H}$ distance

To examine the effect of $\mathrm{E}$ sites on $\mathrm{H}_{2}$ activation by $\mathbf{1}$, we analyzed the profiles of 1-E-P with the activation strain model. We find that that, given a fixed LB partner, the $\mathrm{H}_{2}$ activation barrier follows the order $\mathrm{Ge}>\mathrm{Si}>\mathrm{Sn}$. Qualitatively, this trend is consistent with the experimentally observed reactivity of the 1-E-P FLPs $(\mathrm{E}=\mathrm{Si}, \mathrm{Ge}, \mathrm{Sn})$ towards $\mathrm{CO}_{2} \cdot{ }^{58-60}$ In the case of $\mathrm{H}_{2}$ activation 1-Ge-P has a barrier of value $30.3 \mathrm{kcal} / \mathrm{mol}$ which is quite the highest among all the candidates whereas 1-Si-P and 1-Sn-P has a much lower barrier of value $27.5 \mathrm{kcal} / \mathrm{mol}$ and $21.2 \mathrm{kcal} / \mathrm{mol}$ respectively. In a similar spirit, $\mathbf{1 - G e - N}$ has an activation barrier of value $20.3 \mathrm{kcal} / \mathrm{mol}$ while for $\mathbf{1 - S i - N}$ and 1-Sn-N, TS1 lies at $18.0 \mathrm{kcal} / \mathrm{mol}$ and $14.4 \mathrm{kcal} / \mathrm{mol}$ in energy profile respectively. The ASPs depicted in Figure 8 imply that 1-Sn-P exhibit a lower activation energy barrier owing to higher $\Delta \mathbf{E}_{\text {int }}$ and lower $\Delta \mathbf{E}_{\text {strain. }}$. While for 1-Si-P and 1-Ge-P, the $\Delta \mathbf{E}_{\text {int }}$ almost superimposed along the reaction pathway, the highest energy barrier for 1-Ge-P can be easily justified by its higher value of $\boldsymbol{\Delta} \mathbf{E}_{\text {strain. }}$ A closer examination of the relevant structures reveals that 1-Ge-P suffers from a larger structural distortion to attain the required TS1 geometry compared to 1-Si-P (see Figure S11) which raise its activation barrier compared to others.

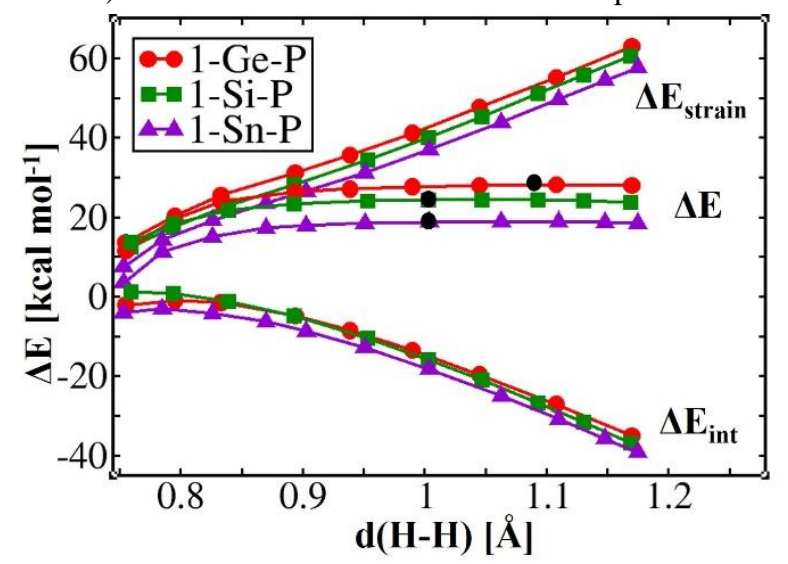

Figure 8. Activation-strain profiles for $\mathrm{H}_{2}$ activation reaction by 1-Si-P (green), 1-Ge-P (red) and 1-Sn-P (violet) along the reaction coordinate projected onto the $\mathrm{H}-\mathrm{H}$ bond length. The black dots represent the respective TSs.
One mechanistic feature that emerges from our detailed analyses is ET involving $\sigma^{*}(\mathrm{R}-\mathrm{E})$ and $\sigma(\mathrm{E}-\mathrm{H})$ orbitals during $\mathrm{H}_{2}$ splitting by these FLPs. In their study of $\mathrm{H}_{2}$ activation by 1-Sn$\mathbf{P}$, Mitzel et al. reported that following $\mathrm{H}-\mathrm{H}$ bond cleavage, the corresponding product $\mathbf{2}$ eventually undergoes a reductive elimination (RE) to form 3 with the removal of $\mathrm{HC}_{2} \mathrm{~F}_{5}{ }^{67}$ This reaction constitutes a deactivation pathway hindering the possible hydrogenation activity of 1-Sn-P by releasing the proton and hydride to an unsaturated organic substrate. Thus, we investigated the mechanism of this relevant deactivation pathway in detail (see Figure 9). We find that the RE from 2 is an extreme manifestation of the ET involving $\sigma^{*}(\mathrm{R}-\mathrm{E})$ and $\sigma(\mathrm{E}-$ $\mathrm{H})$ orbitals during $\mathrm{H}_{2}$ splitting. $\mathrm{NBO}$ analysis of 2 confirms a donor-acceptor interaction between these orbitals $\left(\Delta \mathrm{E}^{(2)}=143.9\right.$ $\mathrm{kcal} / \mathrm{mol}$ ) weakening the corresponding R-E bond. The structure of the TS for the RE (TS2) features an elongated Tr$\mathrm{H}$ bond (for TS2-Sn-P, E-H= $1.76 \AA$, see Figure 9) as a result of the interaction between the carbon centre of the $-\mathrm{R}$ group with the $\sigma^{*}(\mathrm{E}-\mathrm{H})$ orbital. This leads to the gradual rupture of the

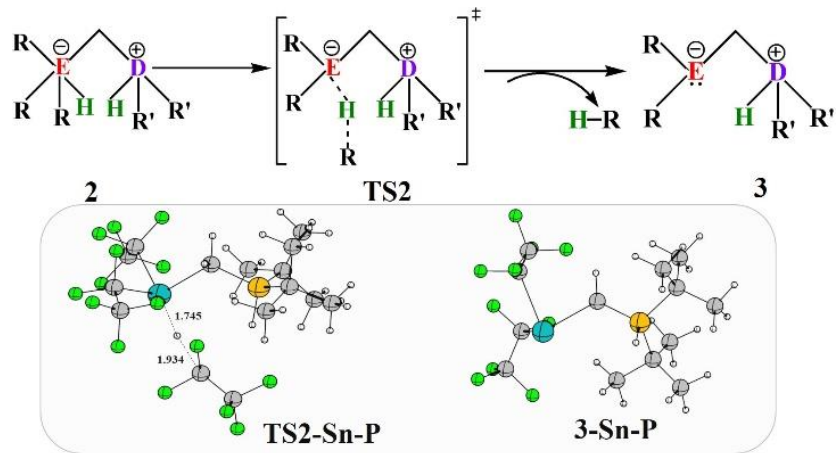

Figure 9. Schematic representation of reductive elimination reaction by $\mathbf{2}$ (top). Geometry optimized structures of the stationary points involved in the reaction by $\mathbf{1 - S n - P}$ (bottom). All distances are given in $\AA$.

Sn-H bond and H-R bond formation takes place followed by the formation of $\mathbf{3}$ and elimination of R-H. Computations show that $\mathrm{RE}$ is strongly exergonic by $30.6 \mathrm{kcal} / \mathrm{mol}$ and 29.5 $\mathrm{kcal} / \mathrm{mol}$ for $\mathbf{2 - S n - P}$ and $\mathbf{2}-\mathbf{S n}-\mathbf{N}$ with respect to their original form 1, with a free energy activation barrier of $27.3 \mathrm{kcal} / \mathrm{mol}$ and $29.4 \mathrm{kcal} / \mathrm{mol}$ respectively. Interestingly, for 2-Si-P and 2Si-N, RE is much less exergonic with $\triangle G_{R}$ (free energy change for the reaction) value of only $7.5 \mathrm{kcal} / \mathrm{mol}$ and $13.0 \mathrm{kcal} / \mathrm{mol}$ with their activation barrier TS2 lies at $31.7 \mathrm{kcal} / \mathrm{mol}$ and 25.0 $\mathrm{kcal} / \mathrm{mol}$, which makes them highly suitable for further catalytic hydrogenation process.

\section{CONCLUSION}

In summary, we have investigated the mechanism of $\mathrm{H}_{2}$ activation by a family of intramolecular FLPs featuring neutral E LA through DFT computations. Our results suggest that the $\mathrm{H}_{2}$ activation follows a concerted pathway through a single fivemembered transition state. NBO analyses reveal that the $\mathrm{E}$ atoms, in absence of a vacant $p$ orbital, utilize the $\sigma^{*}$ orbitals of adjacent bonds as acceptor orbitals. These neutral $\mathrm{E}$ sites derive a considerable Lewis acidity from not only the $\sigma^{*}(\mathrm{R}-\mathrm{E})$ orbital but also from the $\sigma^{*}\left(\mathrm{E}-\mathrm{CH}_{2}\right)$ orbital. A detailed mechanistic investigation confirms that the two cooperative interactions $\mathrm{LP}(\mathrm{D}) \rightarrow \sigma^{*} \mathrm{H}_{2}$ and $\sigma \mathrm{H}_{2} \rightarrow \sigma^{*}\left(\mathrm{E}-\mathrm{CH}_{2}\right) / \sigma^{*}(\mathrm{R}-\mathrm{E})$ are responsible for cleavage of the $\mathrm{H}-\mathrm{H}$ bond. By varying the substituents, the 
LA and the LB centres, we show how to tune the energetics of the $\mathrm{H}_{2}$ activation. In particular, a significant difference in reactivity is observed by swapping the donor site $\mathrm{P}$ to $\mathrm{N}$ since the latter FLPs follow a synchronous mechanism for $\mathrm{H}_{2}$ activation resulting in an early transition state leading to lower activation barriers. Our activation-strain analyses further confirm this difference in reactivity is due to the lower value of strain energy as well as the higher value of interaction energy between the deformed reactants along the entire reaction pathway for the $\mathrm{N}$ bearing FLPs. The origin of such enhanced interactions is also analyzed employing energy decomposition analysis which discloses the stronger electrostatic interaction for FLPs with $\mathrm{N}$ as the donor atom. We have also gauged the influence of different E elements as the LA sites. We find Si and Sn-containing FLPs have much favourable $\mathrm{H}_{2}$ activation energetics compared to those having Ge. This behaviour is rationalized by the ASPs which suggests higher interaction energy and lower strain energy for Si and Sn counterparts compared to their Ge analogue. Further investigation shows that the presence of $\sigma(\mathrm{E}-\mathrm{H}) \rightarrow \sigma^{*}(\mathrm{R}$ E) interaction in the $\mathrm{H}_{2}$-activated product 2 triggers a reductive elimination pathway followed by the elimination of R-H. This pathway could potentially constitute a decomposition route preventing the plausible extension of the $\mathrm{H}_{2}$ activation to hydrogenation catalysis. We expect that the present study provides a general mechanistic framework for $\mathrm{H}_{2}$ activation by this family of FLPs. In fact, considering the free energy profiles, many of these FLP systems have the potential to act as hydrogenation catalysts and investigations along this direction are underway in our laboratory.

\section{COMPUTATIONAL DETAILS}

All electronic structure calculations are performed using M062 $\mathrm{X}^{68,69}$ functional within density functional theory (DFT). In order to account for the non-covalent interactions, Grimme's D3 dispersion model is employed..$^{70}$ For lighter atoms $(\mathrm{C}, \mathrm{H}, \mathrm{N}$, $\mathrm{P}, \mathrm{O}, \mathrm{F})$ we have used 6-311g(d,p) basis set while for the $\mathrm{Si}, \mathrm{Ge}$ and Sn def2TZVP along with Stuttgart-Dresden effective core potential is employed. ${ }^{71}$ This basis set combination is hereafter denoted as BS-I. Harmonic vibrational frequency analysis is performed to characterize the structures to be minima (zero imaginary frequency) or transition states (one imaginary frequency). Transition states (TSs) are further verified by intrinsic reaction coordinate (IRC) calculations to confirm their connection to two respective minimum structures. Based on M062XD3/BS-I optimized geometries, the electronic energies are further refined with single-point energy calculations at the M062X-D3/BS-II level of theory (where, BS-II designates def2TZVP for Si, Ge and $\mathrm{Sn}$ atom and $6-311++\mathrm{g}(\mathrm{d}, \mathrm{p})$ for the lighter atoms). Furthermore, additional single-point computations are also performed with $\omega \mathrm{B} 97 \mathrm{XD}^{72}$ and B3LYP-D3BJ ${ }^{70}$, 73-75 functionals to evaluate the robustness of our results (see TableS2 in the Supporting Information for details). All thermochemical data are obtained with the ideal gas-rigid rotor-simple harmonic oscillator approximations at $298.15 \mathrm{~K}$ and $1 \mathrm{~atm}$. Zero point-energy corrections are included in the Gibbs free energy values along with a concentration correction for $\mathrm{c}=1 \mathrm{~mol} / \mathrm{dm}^{3}$ condition in the solvent. We have used THF as a solvent to estimate the relative stabilities of the reaction intermediates / TS involved in the $\mathrm{H}_{2}$ activation. The SMD solvation model is used to account for the solvent effects. ${ }^{76}$ All natural bond orbital (NBO) analyses are performed using the NBO 3.1 ${ }^{77}$ package. For details of Activation strain analysis and Energy decomposition analysis, see SI. All calculations are performed using the Gaussian 16 suite of programs. ${ }^{78}$

\section{AUTHOR INFORMATION}

\section{Corresponding Author}

Email: pati@jncasr.ac.in

\section{ACKNOWLEDGMENT}

PS acknowledge the Council of Scientific and Industrial Research (CSIR), Govt. of India, for Senior Research Fellowship (SRF).SD thanks JNCASR for the fellowship. SKP also acknowledges J C Bose National fellowship and DST, Govt. of India for the financial support.

\section{REFERENCES}

1. Niu, S.; Hall, M. B., Theoretical Studies on Reactions of Transition-Metal Complexes. Chem. Rev. 2000, 100 (2), 353-406.

2. Torrent, M.; Sola, M.; Frenking, G., Theoretical Studies of Some Transition-Metal-Mediated Reactions of Industrial and Synthetic Importance.Chem. Rev. 2000, 100 (2), 439-494.

3. He, T.; Tsvetkov, N. P.; Andino, J. G.; Gao, X.; Fullmer, B. C.; Caulton, K. G., Mechanism of Heterolysis of $\mathrm{H}_{2}$ by an Unsaturated $\mathrm{d}^{8}$ Nickel Center: via Tetravalent Nickel? J. Am. Chem. Soc. 2010, 132 (3), 910-911.

4. Kimura, T.; Koiso, N.; Ishiwata, K.; Kuwata, S.; Ikariya, T., H$\mathrm{H}$ and $\mathrm{N}-\mathrm{H}$ Bond Cleavage of Dihydrogen and Ammonia with a Bifunctional Parent Imido (NH)-Bridged Diiridium Complex. J. Am. Chem. Soc. 2011, 133 (23), 8880-8883.

5. Camaioni, D. M.; Ginovska-Pangovska, B.; Schenter, G. K.; Kathmann, S. M.; Autrey, T., Analysis of the Activation and Heterolytic Dissociation of $\mathrm{H}_{2}$ by Frustrated Lewis Pairs: $\mathrm{NH}_{3} / \mathrm{BX}_{3}(\mathrm{X}$ = H, F, and Cl). J. Phys. Chem. A 2012, 116 (26), 7228-7237.

6. G. C. Welch; R. R. San Juan; J. D. Masuda; Stephan, D. W., Reversible, Metal-Free Hydrogen Activation. Science 2006, 134 (5802), 1124-1126

7. Preston A. Chase; Welch, G. C.; Jurca, T.; Stephan, D. W., Metal-Free Catalytic Hydrogenation. Angew. Chem. 2007, 119, $8196-8199$.

8. Welch, G. C.; Stephan, D. W., Facile Heterolytic Cleavage of Dihydrogen by Phosphines and Boranes. J. Am. Chem. Soc. 2007, 129 (7), 1880-1881.

9. Stephan, D. W., Frustrated Lewis Pairs. J. Am. Chem. Soc. 2015 , 137 (32), 10018-10032.

10. Stephan, D. W.; Erker, G., Frustrated Lewis Pair Chemistry: Development and Perspectives. Angew.Chem. Int.Ed. 2015, 54, 6400-6441.

11. Erker, G., Frustrated Lewis pairs: Some recent developments. Pure Appl. Chem. 2012, 84 (11), 2203-2217.

12. Stephan, D. W., The broadening reach of frustrated Lewis pair chemistry. Science 2016, 354 (6317), 7229-8.

13. Stephan, D. W.; Erker, G., Frustrated Lewis Pairs: Metal-free Hydrogen Activation and More. Angew. Chem. Int. Ed. 2010, 49, 46-76.

14. Stephan, D. W., Frustrated Lewis Pairs: From Concept to Catalysis. Acc. Chem. Res. 2015, 48 (2), 306-316.

15. Paradies, J., Metal-Free Hydrogenation of Unsaturated Hydrocarbons Employing Molecular Hydrogen. Angew. Chem. Int. Ed. 2014, 53, 3552 - 3557 .

16. Hounjet, L. J.; Stephan, D. W., Hydrogenation by Frustrated Lewis Pairs: Main Group Alternatives to Transition Metal Catalysts? Org. Process Res. Dev. 2014, 18 (3), 385-391.

17. Daniel J. Scott; Fuchter, M. J.; Ashley, A. E., Designing effective 'frustrated Lewis pair' hydrogenation catalysts. Chem. Soc. Rev. 2017, 46, 5689-5700. 
18. Lam, J.; Szkop, K. M.; Mosaferi, E.; Stephan, D. W., FLP catalysis: main group hydrogenations of organic unsaturated substrates. Chem. Soc. Rev. 2019, 48, 3592.

19. Paradies, J., Mechanisms in Frustrated Lewis Pair-Catalyzed Reactions. Eur. J. Org. Chem. 2019, 283-294.

20. Stephan, D. W.; Greenberg, S.; Graham, T. W.; Chase, P.; Hastie, J. J.; Geier, S. J.; Farrell, J. M.; Brown, C. C.; Heiden, Z. M.; Welch, G. C.; Ullrich, M., Metal-Free Catalytic Hydrogenation of Polar Substrates by Frustrated Lewis Pairs. Inorg. Chem. 2011, 50, $12338-12348$

21. Gyömöre, A.; Bakos, M.; Földes, T.; Pápai, I.; Domján, A,; Soós, T., Moisture-Tolerant Frustrated Lewis Pair Catalyst for Hydrogenation of Aldehydes and Ketones. ACS Catal. 2015, 5 (9), 5366-5372.

22. Scott, D. J.; Simmons, T. R.; Lawrence, E. J.; Wildgoose, G. G.; Fuchter, M. J.; Ashley, A. E., Facile Protocol for Water-Tolerant "Frustrated Lewis Pair"-Catalyzed Hydrogenation. ACS Catal. 2015, 5 (9), 5540-5544.

23. Bergquist, C.; Bridgewater, B. M.; Harlan, C. J.; Norton, J. R.; Friesner, R. A.; Parkin, G., Aqua, Alcohol, and Acetonitrile Adducts of Tris(perfluorophenyl)borane: Evaluation of Brønsted Acidity and Ligand Lability with Experimental and Computational Methods. J. Am. Chem. Soc. 2000, 122 (43), 10581-10590.

24. Das, S.; Pati, S. K., On the Mechanism of Frustrated Lewis Pair Catalysed Hydrogenation of Carbonyl Compounds. Chem. Eur. J. 2017, 23, $1078-1085$.

25. Weicker, S. A.; Stephan, D. W., Main Group Lewis Acids in Frustrated Lewis Pair Chemistry: Beyond Electrophilic Boranes. Bulletin of the Chemical Society of Japan 2015, 88, (8).

26. Whittell, G. R.; Balmond, E. I.; Robertson, A. P. M.; Patra, S. K.; Haddow, M. F.; Manners, I., Reactions of Amine- and Phosphane-Borane Adducts with Frustrated Lewis Pair Combinations of Group 14 Triflates and Sterically Hindered Nitrogen Bases. Eur. J. Inorg. Chem. 2010, 3967-3975.

27. Schäfer, A.; Reißmann, M.; Schäfer, D. A.; Saak, W.; Haase, D.; Müller, P. D. T., A New Synthesis of Triarylsilylium Ions and Their Application in Dihydrogen Activation. Angew. Chem. Int. Ed. 2011, 50, 12636 -12638.

28. Herrington, T. J.; Laurence, R. D.; McDermott, J., Andrew, J. P. W.; Hunt, P. A.; Ashley, A. E., Bypassing a highly unstable frustrated Lewis pair: dihydrogen cleavage by a thermally robust silylium-phosphine adduct. Chem. Commun. 2014, 50, 1275312756.

29. Weicker, S. A.; Stephan, D. W., Activation of Carbon Dioxide by Silyl Triflate-Based Frustrated Lewis Pairs. Chem. Eur.J. 2015, $21,13027-13034$.

30. Mallov, I.; Ruddy, A. J.; Zhu, H.; Grimme, S.; Stephan, D. W., C-F Bond Activation by Silylium Cation/Phosphine Frustrated Lewis Pairs: Mono-Hydrodefluorination of $\mathrm{PhCF}_{3}, \mathrm{PhCF}_{2} \mathrm{H}$ and $\mathrm{Ph}_{2} \mathrm{CF}_{2}$. Chem. Eur. J. 2017, 23, $17692-17696$.

31. Clark, E. R.; Ingleson, M. J., N-Methylacridinium Salts: Carbon Lewis Acids in Frustrated Lewis Pairs for $\sigma$-Bond Activation and Catalytic Reductions. Angew. Chem., Int. Ed. 2014, 53, 11306-11309.

32. Mosaferi, E.; Ripsman, D.; Stephan, D. W., The air-stable carbocation salt $\left[\left(\mathrm{MeOC}_{6} \mathrm{H}_{4}\right) \mathrm{CPh}_{2}\right]\left[\mathrm{BF}_{4}\right]$ in Lewis acid catalyzed hydrothiolation of alkenes. Chem. Commun. 2016, 52, 8291.

33. Fasano, V.; Radcliffe, J. E.; Curless, L. D.; Ingleson, M. J., NMethyl-Benzothiazolium Salts as Carbon Lewis Acids for $\mathrm{Si}-\mathrm{H}$ Sigma-Bond Activation and Catalytic (De)hydrosilylation. Chem. Eur. J. 2017, 23, 187-193.

34. Christopher B. C.; Lindsay J. H.; Dobrovetsky, R.; Stephan, D. W., Lewis Acidity of Organofluorophosphonium Salts: Hydrodefluorination by a Saturated Acceptor. Science 2013, 341 (6152), 1374-1377.

35. Zhou, D. J.; Liu, D. L. L.; Cao, L. L.; Stephan, D. W., NitrogenBased Lewis Acids: Synthesis and Reactivity of a Cyclic
(Alkyl)(Amino)Nitrenium Cation. Angew. Chem. Int. Ed. 2018, 57, $3322-3326$

36. Zhou, J.; Liu, L. L.; Cao, L. L.; Stephan, D. W., An umpolung of Lewis acidity/basicity at nitrogen by deprotonation of a cyclic (amino)(aryl)nitrenium cation. Chem. Commun. 2018, 54, 43904393.

37. Mehta, M.; Goicoechea, J. M., Nitrenium Salts in Lewis Acid Catalysis. Angew. Chem. 2020, 132, $2737-2741$

38. Avigdori, I.; Pogoreltsev, A.; Kaushanski, A.; Fridman, N.; Gandelman, M., Frustrated Lewis Pairs Comprising Nitrogen Lewis Acids for $\mathrm{Si}-\mathrm{H}$ Bond Activation. Angew. Chem. Int. Ed. 2020, 59, $23476-23479$.

39. Pérez, M.; Hounjet, L. J.; Caputo, C. B.; Dobrovetsky, R.; Stephan, D. W., Olefin Isomerization and Hydrosilylation Catalysis by Lewis Acidic Organofluorophosphonium Salts. J. Am. Chem. Soc. 2013, 135, 18308-18310.

40. Stein, V. T.; Peréz, M.; Dobrovetsky, R.; Winkelhaus, D.; Caputo, C. B.; Stephan, D. W., Electrophilic Fluorophosphonium Cations in Frustrated Lewis Pair Hydrogen Activation and Catalytic Hydrogenation of Olefins. Angew.Chem. Int. Ed. 2015, 54, 10178 -10182 .

41. Fasano, V.; LaFortune, J. H. W.; Bayne, J. M.; Ingleson, M. J.; Stephan, D. W., Air- and water-stable Lewis acids: synthesis and reactivity of P-trifluoromethyl electrophilic phosphonium cations. Chem. Commun. 2018, 54, 662.

42. Postle, S.; Podgorny, V.; Stephan, D. W., Electrophilic phosphonium cations (EPCs) with perchlorinated-aryl substituents: towards air-stable phosphorus-based Lewis acid catalysts. Dalton Trans. 2016, 45, 14651.

43. Barrado, A. G.; Bayne, J. M.; Johnstone, T. C.; Lehmann, C. W.; Stephan, D. W.; Alcarazo, M., Dicationic phosphonium salts: Lewis acid initiators for the Mukaiyama-aldol reaction. Dalton Trans. 2017, 46, 16216.

44. Bayne, J. M.; V. Fasano; Szkop, K. M.; Ingleson, M. J.; Stephan, D. W., Phosphorous(v) Lewis acids: water/base tolerant $\mathrm{P}_{3}$-trimethylated trications. Chem. Commun. 2018, 54, 12467.

45. Scott, D. J.; Phillips, D. N. A.; Sapsford, J. S.; Deacy, A. C.; Fuchter, M. J.; Ashley, A. E., Versatile Catalytic Hydrogenation Using A Simple Tin(IV) Lewis Acid. Angew. Chem. Int. Ed. 2016, $128,14958-14962$.

46. Robert T. Cooper; Joshua S. Sapsford; C., R.; Ritson, T.; Hyon, D.; White, A. J. P.; Ashley, A. E., Hydrogen activation using a novel tribenzyltin Lewis acid. Phil. Trans. R. Soc. A. 2017, 375. 47. Grimme, S.; Kruse, H. Goerigk, L.; Erker, G., The Mechanism of Dihydrogen Activation by Frustrated Lewis Pairs Revisited. Angew. Chem. Int. Ed. 2010, 49, $1402-1405$.

48. Rokob, T. A.; Hamza, A.; Stirling, A.; Soos, T.; Papai, I., Turning Frustration into Bond Activation: A Theoretical Mechanistic Study on Heterolytic Hydrogen Splitting by Frustrated Lewis Pairs. Angew. Chem. Int. Ed. 2008, 47, $2435-2438$.

49. Hamza, A.; Stirling, A.; Rokob, T. A.; Pápai, I., Mechanism of hydrogen activation by frustrated Lewis pairs: A molecular orbital approach. International Journal of Quantum Chemistry. 2009, 109, $2416-2425$

50. Rokob, T. A.; Hamza, A.; Stirling, A.; Pápai, I., On the Mechanism of $\mathrm{B}\left(\mathrm{C}_{6} \mathrm{~F}_{5}\right)_{3}$-Catalyzed Direct Hydrogenation of Imines: Inherent and Thermally Induced Frustration. J. Am. Chem. Soc. 2009, 131 (5), 2029-2036.

51. Rokob, T. A.; Hamza, A.; Papai, I., Rationalizing the Reactivity of Frustrated Lewis Pairs: Thermodynamics of $\mathrm{H}_{2}$ Activation and the Role of Acid-Base Properties. J. Am. Chem. Soc. 2009, 131 (30), 10701-10710.

52. Rokob, T. A.; Bako, I.; Stirling, A.; Hamza, A.; Pápai, I., Reactivity Models of Hydrogen Activation by Frustrated Lewis Pairs: Synergistic Electron Transfers or Polarization by Electric Field? J. Am. Chem. Soc. 2013, 135 (11), 4425-4437. 
53. Rokob, T. A.; Pápai, I., Hydrogen Activation by Frustrated Lewis Pairs: Insights from Computational Studies. Top. Curr. Chem. 2013, 332, 157-211.

54. Das, S.; Mondal, S.; Pati, S. K., Mechanistic Insights into Hydrogen Activation by Frustrated N/Sn Lewis Pairs. Chem. Eur. J. 2018, 24, $2575-2579$.

55. Das, S.; Pati, S. K., Unravelling the mechanism of tin-based frustrated Lewis pair catalysed hydrogenation of carbonyl compounds. Catal. Sci. Technol. 2018, 8, 5178.

56. Sapsford, J. S.; Csókás, D.; Scott, D. J.; R. C. Turnell-Ritson; Piascik, A. D.; Pápai, I.; Ashley, A. E., Establishing the Role of Triflate Anions in $\mathrm{H}_{2}$ Activation by a Cationic Triorganotin(IV) Lewis Acid. ACS Catal. 2020, 10 (14), 7573-7583.

57. Das, S.; Pati, S. K., Computational Exploration of Intramolecular Sn/N Frustrated Lewis Pairs for Hydrogen Activation and Catalytic Hydrogenation. Organometallics 2021, 40 (2), 194-202.

58. Waerder, B.; Pieper, M.; Körte, L. A.; Kinder, T. A.; Mix, A.; Neumann, B.; Stammler, G-H.; Mitzel, N. W., A Neutral Silicon/Phosphorus Frustrated Lewis Pair. Angew. Chem. Int. Ed. 2015, 54, $13416-13419$.

59. Kinder, T. A.; Pior, R.; Blomeyer, S.; Neumann, B.; Stammler, G-H.; Mitzel, N. W., A Neutral Germanium/Phosphorus Frustrated Lewis Pair and Its Contrasting Reactivity Compared to Its Silicon Analogue. Chem. Eur. J. 2019, 25, 5899-5903.

60. Holtkamp, P.; Friedrich, F.; Stratmann, E.; Mix, A.; Neumann, B.; Stammler, G-H.; Mitzel, N. W., A Neutral Geminal Tin/Phosphorus Frustrated Lewis Pair. Angew.Chem. Int. Ed. 2019, 58, 5114 -5118 .

61. Presumably one advantage of these FLP combinations is their neutral from compared to the corresponding tetrylium-based FLPs which are accompanied by a counter anion for charge neutrality additionally complicating the reaction pathways.

62. Waerder, B.; Steinhauer, S.; Bader, J.; Neumann, B.; Stammler, G-H.; Vishnevskiy, Y. V.; Hoge, B.; Mitzel, N. W., Pentafluoroethyl-substituted $\alpha$-silanes: model compounds for new insights. Dalton Trans. 2015, 44.

63. Mitzel, N. W.; Vojinovic, K.; Foerster, T.; Robertson, H. E.; Borisenko, K. B.; Rankin, D. W. H., (Dimethylaminomethyl)trifluorosilane, $\mathrm{Me}_{2} \mathrm{NCH}_{2} \mathrm{SiF}_{3}-\mathrm{A}$ Model for the $\alpha$-Effect in Aminomethylsilanes. Chem. Eur. J. 2005, 11, $5114-5125$.

64. Kinder, T. A.; Blomeyer, S.; Franke, M.; Depenbrock, F.; Neumann, B.; Stammler, G-H.; Mitzel, N. W., Small Neutral Geminal Silicon/Phosphorus Frustrated Lewis Pairs. Eur. J. Inorg. Chem. 2019, 35, 3933-3939.

65. Bertini, F.; Lyaskovskyy, V.; Timmer, B. J. J.; Kanter, F. J. J. d.; Lutz, M.; Ehlers, A. W.; Slootweg, J. C.; Lammertsma, K., Preorganized Frustrated Lewis Pairs. J. Am. Chem. Soc. 2012, 134 (1), 201-204.

66. Cabrera-Trujillo, J. J.; Fernandez, I., Understanding the Reactivity of Neutral Geminal Group 14 Element/Phosphorus Frustrated Lewis Pairs. J. Phys. Chem. A. 2019, 123 (46), 10095-10101.
67. Holtkamp, P.; Schwabedissen, J.; Neumann, B.; Stammler, GH.; Koptyug, I. V.; Zhivonitko, V. V.; Mitzel, N. W., A Zwitterionic Phosphonium Stannate(II) via Hydrogen Splitting by a Sn/P Frustrated Lewis-Pair and Reductive Elimination. Chem. Eur. J. 2020, 26, $17381-17385$.

68. Zhao, Y.; Truhlar, G. D., The M06 suite of density functionals for main group thermochemistry, thermochemical kinetics, noncovalent interactions, excited states, and transition elements: two new functionals and systematic testing of four M06-class functionals and 12 other functionals. Theor. Chem. Account. 2008, 120, 215-241.

69. Zhao, Y.; Truhlar, G. D., Density functionals with broad applicability in chemistry. Acc. Chem. Res. 2008, 41, 157-167.

70. Grimme, S.; Antony, J.; Ehrlich, S.; Krieg, H., A consistent and accurate $a b$ initio parametrization of density functional dispersion correction (DFT-D) for the 94 elements H-Pu. J. chem. phys. 2010, 132, 154104-154119.

71. Andrae, D.; Haeussermann, U.; Dolg, M.; Stoll, H.; Preuss, H., Energy-adjusted ab initio pseudopotentials for the second and third row transition elements. Theor. Chem. Account. 1990, 77, 123-141. 72. Chai, J-D.; Head-Gordon, M., Long-range corrected hybrid density functionals with damped atom-atom dispersion corrections. Phys. Chem. Chem. Phys. 2008, 10, 6615-6620.

73. Becke, A. D., A new mixing of Hartree-Fock and local density functional theories. J. Chem. Phys. 1993, 98, 1372-1377.

74. C. Lee; Yang, W.; Parr, R. G., Development of the ColleSavetti correlation-energy formula into a functional of the electron density. Phys. Rev. B 1988, 37.

75. Miehlich, B.; Savin, A.; Stoll, H.; Preuss, H., Results obtained with the correlation energy density functionals of Becke and Lee, Yang and Parr. Chem. Phys. Lett. 1989, 157, 200-206.

76. Marenich, A. V.; Cramer, C. J.; Truhlar, D. G., Universal solvation model based on solute electron density and on a continuum model of the solvent defined by the bulk dielectric constant and atomic surface tensions. J. Phys. Chem. B. 2009, 113, 6378-639.

77. Glendening, D. E.; Reed, A. E.; Carpenter, J. E.; Weinhold, F., NBO, version 3.1.

78. Frisch, M. J. et al., Gaussian 16 Revision A.03. 2016; Gaussian Inc. Wallingford CT. 